\title{
Language, gender and sexuality in Japanese popular media
}

\author{
Momoko Nakamura
}

Studies of non-Western contexts have become increasingly important in research investigating how the situated enactments of gender and sexuality intersect with national, cultural and racial configurations. As Hall, Borba and Hiramoto (forthcoming) point out in a recent review of gender and language research, these studies have the potential to relativise Westernbased frameworks by providing a crucial corrective to Eurocentric assumptions. Japanese researchers have made considerable contributions to the field of language, gender and sexuality in this regard, supplying analyses of discourse practices and ideologies that do not always align with perspectives found in European and North American scholarship.

Given the socially salient notion of Japanese women's language, much of this work has scrutinised the complex relationships among femininity, linguistic features and language ideologies (see, e.g., papers in Okamoto and Shibamoto Smith 2004; Inoue 2006; Asano-Cavanagh 2014). Other studies have further responded to recent sociolinguistic and linguistic anthropological interests in mediatised discourse, situating relations between gender, language and ideology in Japanese and other East Asian contexts (e.g. Shibamoto Smith and Occhi 2009; Hiramoto and Kang 2017). Nevertheless, there has been scarce research on the linguistic representation of masculinities in Japanese media, with few exceptions (Occhi, SturtzSreetharan and Shibamoto-Smith 2010; Robertson 2017; SturtzSreetharan 2017a, 2017b; Dahlberg-Dodd 2018).

\footnotetext{
Affiliation

Kanto Gakuin University.

email: momo@kanto-gakuin.ac.jp
}

G\&L VOL $14.3 \quad 2020 \quad 221-225$

(C) 2020, EQUINOX PUBLISHING 
This special issue seeks to build on the evolving body of scholarship on mediatised representations of gender and sexuality by putting emphasis on traditional and emerging Japanese masculinities as well as femininities. The six papers collected here approach mediatised representations of gender and sexuality from three perspectives that become possible by analysing data in a language other than English, namely, Japanese.

The first two papers examine the ways that whiteness is linguistically represented in Japanese popular contemporary media. In contrast to the abundant research on the ways non-Western races are presented in the West, there are few studies on representations of white races in nonWestern contexts. Satoko Suzuki's paper analyses the Japanese speech of non-Japanese male characters in contemporary Japanese novels, finding that Japanese authors assign masculine linguistic features much more frequently to their East Asian characters than to their white characters. Furthermore, through their masculine language, East Asian men are constructed as more heterosexually attractive than white men, in contrast to the longstanding Western stereotype of Asian men as feminine and asexual. Momoko Nakamura's quantitative analysis of a self-report survey and accompanying examination of the translated speech of non-Japanese males in an American TV drama, Beverly Hills, 90210, shows that Japanese translators have created a sociolinguistic style that is linked to cool, informal, non-Japanese masculinity. Adopted as the speech of impolite, irresponsible, non-Japanese men in the Japanese parody of the TV show, this style enregisters a negative stereotype of non-Japanese masculinity, which serves to legitimate and sustain a polite, formal, Japanese hegemonic masculinity. These papers reveal the unexpected ideological roles white and East Asian masculinities play in the Japanese context, demonstrating the importance of researching gendered, sexual and racial configurations in non-Western contexts.

The next two papers of this special issue take on the newly emerging Japanese masculinities of the sengyōshufu 'househusband' and ikumen 'childrearing man/men', showing how mediatised discourses evaluate and criticise new types of masculinity in comparison with the Japanese hegemonic masculinity of sarariman 'salaried man/men'. Chie Fukuda's analysis of discourse about househusbands on two Japanese TV talk shows broadcast in 2009 and 2015 demonstrates that people evaluate househusbands in contrast with sarariman masculinity, formulating househusbands as unusual, controversial and not fully accepted in society. At the same time, participants on the shows display both resistance and orientation to sarariman masculinity, suggesting that the hegemonic gendered division of labour is in the process of transition. Likewise, Junko Saito's study of the 2015 Japanese TV drama Age Harassment reveals how sarariman 
characters perform sarariman masculinity by negatively evaluating not only women co-workers but also an ikumen 'childrearing man' co-worker. The study illuminates a hierarchy within sarariman masculinities of dominant corporate warrior sarariman and subordinate childrearing sarariman. Meanwhile, the drama's audience, who self-identify as female in the online commentary that provides data for the analysis, criticise sarariman characters' sexist evaluations of women alongside ikumen masculinity as depicted in the drama. Saito concludes that corporate warrior sarariman, who prioritise work over family, are still to some degree accepted as the hegemonic ideal in contemporary Japan. These papers demonstrate that there are significant sociopolitical changes related to gender and sexuality occurring in Japanese society which are in conversation with Western notions of gender equality. The media play a considerable role in both reasserting and shifting traditional gender regimentation.

The last two papers take two notions of Japanese origin that have come to be globally recognised, kawaii and manga, and explore how they are enacted and represented in Japanese media within the local context of Japan itself. Natalia Konstantinovskaia's multimodal analysis of television advertisements for hygiene products and cosmetics aired between 2012 and 2017 shows that the ads' depictions of women layer together three distinct ideologies often viewed as mutually exclusive: kawaii ideals of innocence, ignorance and immaturity; the traditional gender order of male dominance and female submissiveness; and the postfeminist ideal of strong, independent women. Nevertheless, the tensions between these ideologies serve to maintain the hegemony of kawaii vulnerability. Giancarla Unser-Schutz's analysis of online posts from Yahoo! Chiebukuro - the popular Japanese version of Yahoo! Answers - shows that language used in manga is often criticised for its lack of sophistication, lack of authenticity and negative impact on the speech of those who read manga. These negative evaluations of language in manga are easily refutable, suggesting that they are the result of a process whereby people expand negative stereotypes of manga readers, known as otaku 'nerds/fans', to manga itself.

Drawing from various methodological approaches that include membership categorisation analysis, linguistic anthropology, translation studies and other forms of socially oriented discourse analysis, these papers provide compelling sociolinguistic analyses of Japan by shedding light on the intersectional frictions that constitute its mediatised gendered, sexual and racial regimes. Importantly, they throw into sharper relief the conflictual relations between traditional and innovative discursive orders. With vivid empirical detail, the papers in this special issue illuminate how Japanese media perpetuates and modifies images of women and men through 
representations that draw from enduring as well as emergent meanings in the identity repertoire of contemporary Japan.

\section{Acknowledgements}

This special issue is a collection of papers based on presentations at the Ninth International Gender and Language Association Conference, held at City University of Hong Kong in May 2016. Special thanks must go to John Ingulsrud, Shoichi Iwasaki, Laura Miller, Shigeko Okamoto, Scott Saft, Stephanie Schnurr, Janet Shibamoto-Smith, Cindi SturtzSreetharan and Andrew Wong for anonymously reviewing and giving valuable comments on the early draft of each paper. I'm also grateful to Mie Hiramoto, Rodrigo Borba, Kira Hall, Tommaso Milani, Brian King and Phoebe Pua for providing guidance and feedback.

\section{References}

Asano-Cavanagh, Yuko (2014) Linguistic manifestation of gender reinforcement through the use of the Japanese term kawaii. Gender and Language 8(3): 341-59. https://doi.org/10.1558/genl.v8i3.341

Dahlberg-Dodd, Hannah E. (2018) Voices of the hero: dominant masculine ideologies through the speech of Japanese shönen protagonists. Gender and Language 12(3): 346-371. https://doi.org/10.1558/genl.32536

Hall, Kira, Borba, Rodrigo and Hiramoto, Mie (forthcoming) Language and gender. In James M. Stanlaw (ed) The International Encyclopedia of Linguistic Anthropology. Hoboken, NJ: Wiley.

Hiramoto, Mie and Kang, M. Agnes (eds) (2017) Media articulations of gender and sexuality. [Special issue]. Gender and Language 11(4): 453-459.

https://doi.org/10.1558/genl.32536

Inoue, Miyako (2006) Vicarious Language: Gender and Linguistic Modernity in Japan. Berkeley: University of California Press.

Occhi, Debra J., Sturtzsreetharan, Cindi L. and Shibamoto-Smith, Janet S. (2010) Finding Mr Right: new looks at gendered modernity in Japanese televised romances. Japanese Studies 30(3): 413-429. https://doi.org/10.1080/10371397.2010.518605

Okamoto, Shigeko and Shibamoto Smith, Janet S. (eds) (2004) Japanese Language, Gender, and Ideology: Cultural Models and Real People. Oxford: Oxford University Press.

Robertson, Wesley (2017) He's more katakana than kanji: indexing identity and self presentation through script selection in Japanese manga (comics). Journal of Sociolinguistics 21(4): 497-520. https://doi.org/10.1111/josl.12246

Shibamoto Smith, Janet S. and Occhi, Deborah (2009) The green leaves of love: Japanese romantic heroines, authentic femininity, and dialect. Journal of Sociolinguistics 13(4): 524-546. 
SturtzSreetharan, Cindi L. (2017a) Academy of devotion: performing status, hierarchy, and masculinity on reality TV. Gender and Language 11(2): 176-203. https://doi.org/10.1558/genl.21361

SturtzSreetharan, Cindi L. (2017b) Language and masculinity: the role of Osaka dialect in contemporary ideals of fatherhood. Gender and Language 11(4): 552-574. https://doi.org/10.1558/genl.31609 